Andrzej KŁOS ${ }^{1}$

\title{
DETERMINATION OF SORPTION PROPERTIES OF HEAVY METALS IN VARIOUS BIOSORBENTS
}

\author{
WYZNACZANIE PARAMETRÓW SORPCJI METALI CIĘ̇̇KICH \\ W RÓŻNYCH BIOSORBENTACH
}

\begin{abstract}
Various techniques of determination of properties of physicochemical processes of heavy metal sorption in biosorbents were analysed. The methods of preparing and storing samples, conditions of experiment performance, as well as the methods of data interpretation were discussed. Two procedures of study were analysed: (1) in the static system of biosorbent-solution contact and (2) in the system of dynamic flow of solution. Copper cation sorption was studied. The effect of consecutive stages of the study on the quality of final results was shown. A high degree of uncertainty of the sorption capacity assessment was reported, which was dependent on the manner of conducting the study. The application of the pseudo-second order reaction model was substantiated to describe kinetics of cation-exchange sorption and the model of Langmuir isotherm to describe equilibria. The study conducted reveals that in order to perform comparative analyses, it is necessary to establish a joint concept of conducting studies and the interpretation of results.
\end{abstract}

Keywords: biosorption, heavy metal, kinetics, equilibria, analytical procedures, results interpretation

\section{Introduction}

In recent years, studies results on heavy metal sorption in biomass have been frequently published. The kinetics and process equilibrium have been studied, e.g. [1], the sorption capacity was determined, e.g. [2], as well as the conditions for optimal sorption of heavy metals in solutions, e.g. mercury sorption in marine algae [3]. It has been found that one of the mechanisms of heavy metal cation sorption in biomass is ion-exchange: in lichen [4] and moss [5], aquatic moss [6], algae [7] and microorganisms [8]. The authors also point to the possibility of metal cations complexing as well as physical adsorption [9].

An important aim of this study is to evaluate the possibilities of biomass application in the process of remediation, e.g. [10]. Such studies use the waste biological material, which is often physically and chemically modified, e.g. [11] and modified natural mineral sorbents $[12,13]$. These results are also helpful in primary studies regarding the sorption properties of organisms used in biomonitoring of environmental pollution [14].

The literature reveals the lack of a homogeneous concept regarding the experimental methodology. The studies of sorption processes on variously prepared biological materials

\footnotetext{
${ }^{1}$ Chair of Biotechnology and Molecular Biology, University of Opole, ul. kard. B. Kominka 6, 45-032 Opole, Poland, phone +48 7740160 42, email: aklos@ uni.opole.pl
} 
are carried out under static conditions e.g. [15], with various proportions of biosorbent mass and volume of solution in which it was immersed, but also under dynamic conditions, e.g. [16], in which the sorbent is rinsed with the solution of specified parameters of flow rate and contact time. The results obtained from different study methods are difficult to compare since various interpretation standards are frequently applied.

Equilibrium parameters are most frequently described by the Langmuir isotherm model, e.g. in moss [17], algae [18] and other biological materials which are waste from the food production process; e.g. in husks of Cicer arientinum [19], and are described by the Freudlich model, e.g. in lichen [20], and less frequently in the Dubinin and Raduszkiewicz model [21] and Temkin model [22]. A study regarding the adjustment of 10 different isotherm models to describe the equilibrium of $\mathrm{Cu}, \mathrm{Cd}$ and $\mathrm{Pb}$ sorption in cyanobacteria was presented by Dhananjay Kumar et al. [23]. Most authors show that the best adjustment was revealed in the Langmuir isotherm model; however, the Freudlich model, e.g. [20] and the Toth model [23] are also mentioned. The problem is that the authors rarely provide information on the uncertainty of sorption capacity measurements results. For instance, the sorption capacity of the alga Spirogyra sp. for copper cations is $133 \mathrm{mg} / \mathrm{g}$ [24], and the alga Spirogyra insignis only $19.1 \mathrm{mg} / \mathrm{g}$ [25]. Frequently, the only given statistical parameter is the $R^{2}$ determination coefficient $[21,22,26]$, which does not unequivocally suggest the uncertainty of determinations.

The kinetics of sorption taking place due to ion-exchange is described by the pseudo-first order rate equation and more frequently by the pseudo-second order rate equation [21, 26-28]. These models are used to determine the constants of the reaction rate. This parameter, similar to the sorption capacity, is required to assess the possibility of the practical application of biosorbents [29]. Frequently, the effect of temperature on the biosorption processes is also studied. By means of the Arrhenius equation, thermodynamic parameters are assessed, e.g. the biosorption activation energy, e.g. [30]. Also here, the only statistical parameter given is the $R^{2}$ determination coefficient.

This paper is a companion of empirical knowledge obtained in the long process of conducting and publishing our own studies, e.g. [31], supplemented by the results of experiments carried out for this particular purpose. The aim of the analyses is assessment of the effect of sample preparation and storage on the changes in sorption properties, the effect of hydrogen cations on heavy metals sorption as well as the effect of experiment conditions on the properties to be determined. The assessment of the uncertainty of equilibrium and kinetics parameters determination of the ion-exchange process will also be commented on. The presented results concern the sorption properties of copper cations. Copper was chosen due to its good affinity with the active centres of the studied biosorbents and slight uncertainty of measurements.

\section{Materials and methods}

The study used various biosorbents: lichens Hypogymnia physodes, moss Pleurozium schreberi, freshwater alga Spirogyra sp. and saltwater alga Palmaria palmate. Collected moss and lichen samples were cleaned from mechanical impurities and, after drying at the temperature of $323 \mathrm{~K}$, were stored in airtight polyethylene containers. Also, the saltwater alga Palmaria palmate, purchased as merchandise goods from the company Bogutyn Mlyn from Radzyn Podlaski (Poland), were stored in polyethylene containers. Further preparation of moss, lichen and saltwater alga samples, similarly to the freshly collected alga Spirogyra 
sp., depended on the detailed aims of the study to be conducted. A short description of the final sample preparation can be found in each subchapter concerning the presented results. The applied analyte proportions were also defined together with the manner of conducting the study: in conditions of a static biosorbent-solution contact, or in conditions of dynamic solution flow.

\section{Static and dynamic conditions of study}

In the static system, the biosorbents samples (the mass dependent on the purpose of the study) were immersed in the copper sulphate solution of $200 \mathrm{~cm}^{3}$. The solution was stirred intensely with a magnetic stirrer. The process was carried out for 30-50 min, depending on the sorbent applied. The changes of copper concentrations were determined in the solution.

In the dynamic system, the biosorbents samples were placed in a container through which the copper sulphate solution was permeated at app. $200 \mathrm{~cm}^{3} / \mathrm{min}$, providing constant concentration of copper cations in the solution in which the biosorbent was immersed. The process took place for $40 \mathrm{~min}$. Copper was determined in the initial solution and in biosorbents prior to and after the sorption.

\section{Equipment and reagents}

To determine copper, the SOLAAR 969 atomic absorption spectrometer from UNICAM manufactured by Thermo Electron Corporation, USA was used. Calibration of the spectrometer was performed with standard solutions from ANALYTIKA Ltd. (Czech Republic). The value of the highest standard copper solution used for calibration equalling $5 \mathrm{mg} / \mathrm{dm}$ was assumed as the threshold of linear dependence between the signal and concentration. To examine the $\mathrm{pH}$ of solutions in which biosorbents were immersed, the $\mathrm{pH}$ meter CP551 manufactured by Elmetron Sp.j. from Zabrze (Poland) was used, which had an absolute error of readings of: $\Delta \mathrm{pH}=0.02$. Biosorbents $(0.4 \mathrm{~g}$ of dry mass $)$ were mineralised in the mixture of nitric acid and hydrogen peroxide in the MARS-X microwave oven manufactured by CEM. The solutions were prepared with the MERCK reagents.

\section{Quality control}

The quality control of measurements was assured by test analyses of the BCR 414 plankton and BCR-482 lichen reference materials from the Institute for Reference Materials and Measurements in Belgium. The obtained results are summarised in Table 1.

Measured and certified values of $\mathrm{Cu}$ concentration in the BCR 414 plankton and BCR 482 lichen reference material; $q_{v}$ - certified value, $U$ - uncertainty; $S D$ - standard deviation, $D$ - deviation: the relative difference between measured by AAS and certified concentrations in [\%]

\begin{tabular}{|c|c|c|c|c|c|c|c|c|c|}
\hline \multicolumn{5}{|c|}{ BCR 414 plankton } & \multicolumn{5}{|c|}{ BCR 482 lichen } \\
\hline \multirow[b]{2}{*}{$q_{v}$} & \multirow{2}{*}{ $\pm U$} & \multicolumn{2}{|c|}{ AAS } & \multirow{2}{*}{$D$} & \multirow[b]{2}{*}{$q_{v}$} & \multirow{2}{*}{ $\pm U$} & \multicolumn{2}{|c|}{ AAS } & \multirow{2}{*}{$D$} \\
\hline & & Mean & $\pm S D$ & & & & Mean & $\pm S D$ & \\
\hline \multicolumn{4}{|c|}{$[\mu \mathrm{g} / \mathrm{g}]$} & [\%] & \multicolumn{4}{|c|}{$[\mu \mathrm{g} / \mathrm{g}]$} & {$[\%]$} \\
\hline 29.5 & 1.3 & 27.8 & 1.9 & -5.8 & 7.03 & 0.19 & 6.54 & 0.18 & -7.0 \\
\hline
\end{tabular}




\section{Results and discussion}

The presented results have been systematised in accordance with successive stages of the study: the sample collection stage, the analyses stage preceded by the assessment of hydrogen cations effect on sorption processes and the stage of interpretation and assessment of results uncertainty.

\section{Effect of samples preparation and storage on their sorption properties}

The preparation of biological material usually consisted of separating it from mechanical impurities, sometimes rinsing with water and drying into a solid mass in the process of thermal vaporisation of water from, e.g. algae [27], or in the process of lyophilisation [32]. Cleaned and dried samples were stored in paper containers or tightly closed plastic containers [3].

Frequently, in order to average the system, the samples were homogenised in mortar grinders [3]. Sometimes, the homogenised biological material immobilised on various carriers, e.g. polisilicates [5].

Our own studies show that averaging the content of mobile cations bound in biosorbent may be achieved by bathing it in demineralised water. Physical substances bound on the surface dissolve in water, provoking the ion-exchange process, which, as a consequence, causes averaging of the content of mobile cations bound with the active centres in the whole biosorbent mass. While stirring intensely, satisfying results were obtained after $30 \mathrm{~min}$ of bathing. This did not cause mechanical damage of cellular structures. It may also be used to saturate the active centres with required cations, e.g.: $\mathrm{H}^{+}, \mathrm{Na}^{+}, \mathrm{K}^{+}, \mathrm{Mg}^{2+}$ and $\mathrm{Ca}^{2+}[33]$.

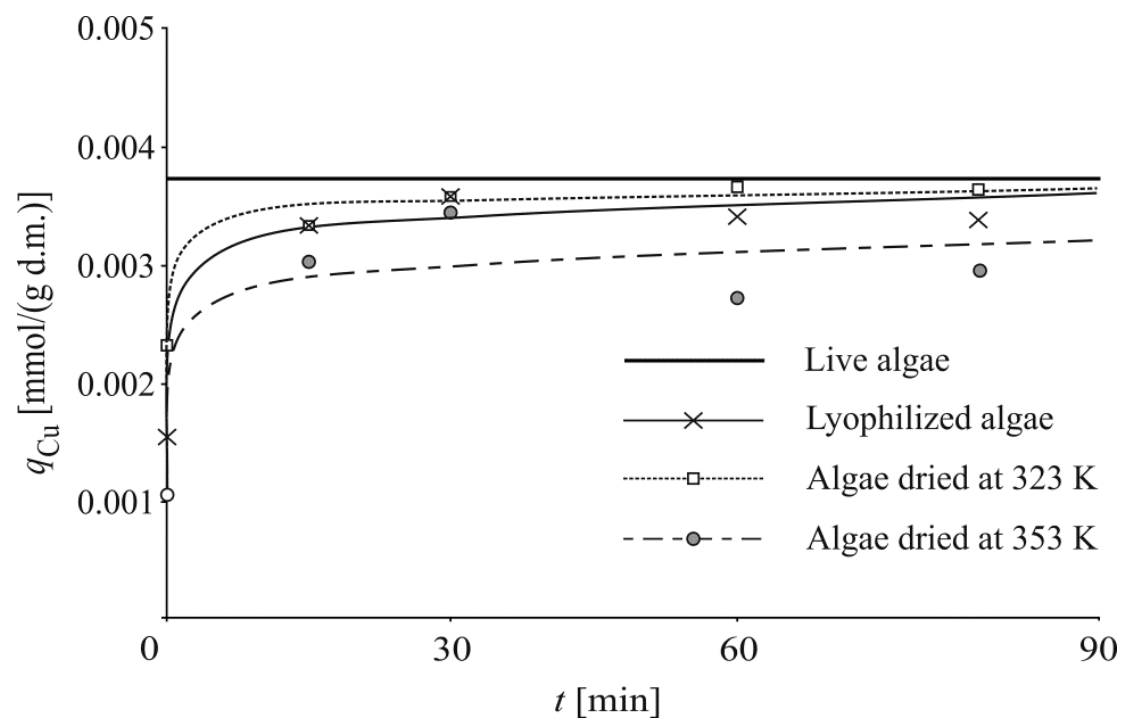

Fig. 1. Influence of time of alga conditioning in demineralised water on the sorption properties (for $t=0$ the algae were not conditioned) [34] 
Improvement of sorption properties, especially in the case of algae, was achieved in the process of sample conditioning in demineralised water directly prior to the experiment [34]. Examples of changes in the sorption properties of algae Spirogyra sp. in relation to conditioning time in water, before the actual experiment, are shown in Figure 1. Alga samples with the mass of $0.4 \mathrm{~g}$ d.m. (dry mass) were immersed in $200 \mathrm{~cm}^{3}$ of copper sulphate with the initial concentration of $0.017 \mathrm{mmol} / \mathrm{dm}^{3}$. For the purpose of comparison, the Figure presents the average concentration value of copper absorbed in the same conditions on living algae.

The results indicate that the lyophilised algae and the algae dried at $323 \mathrm{~K}$ should be immersed in demineralised water for at least $15 \mathrm{~min}$ to reach the proper sorption properties. The algae dried at $353 \mathrm{~K}$ generally had slightly worse sorption properties. The need to condition the alga samples in demineralised water prior to sorption has also been suggested by other authors $[2,35]$.

An easy way to assess the irreversible changes taking place in biosorbents, which are stored for too long, is to perform conductometry of the demineralised water in which a sample is immersed. This was used e.g. to assess the destruction of lichen cell membranes, which takes place under the influence of contamination of the atmospheric aerosol [36]. On the basis of the alga Spirogyra spp., it was reported that water conductivity after a 180-minute contact with the samples of prepared algae compared to living algae increased in the series: living algae < lyophilised algae $\approx$ algae dried at $323 \mathrm{~K}<$ algae dried at $353 \mathrm{~K}<$ algae dried at $323 \mathrm{~K}$ and stored for 30 days [34]. The sorption properties of algae change in the reversed series. Some studies report better sorption properties of dead biomass, e.g. of alga Chlorella vulgaris [37].

To conclude, even at the stage of sample preparation and storage, changes in sorption properties may appear, which can be assessed by changing the conductivity of demineralised water in which the biosorbent is immersed. Prior to the performance of appropriate analyses, the conditioning of dried biosorbents in demineralised water may have an effect on the course of the sorption process.

\section{Effect of hydrogen cations on sorption processes}

The effect of $\mathrm{pH}$ on the sorption properties of heavy metals in biomass in lichen, e.g. [38], moss, e.g. [39] and algae, e.g. [40] is widely recognised. Most study results show that the maximum sorption of heavy metals is achieved for $\mathrm{pH}$ ranging from 4 to 6 , depending on the type of absorbed metal, its initial concentration and the applied sorbent. Usually, a decrease of heavy metal sorption in acidic solutions is explained by a competitive sorption of hydrogen cations, while in alkaline solutions, this is due to the creation of hydrocomplexes, insoluble metal compounds, mainly hydroxides, as well as the blockade of active centres or the change in the ion form of metals [3, 21, 38, 41, 42]. It should be pointed out that this is in accordance with the formula: $\mathrm{pH}_{\text {prec. }}=z^{-1} \cdot\left(14 \cdot z-\log c_{\mathrm{Me}}+z-\mathrm{p} K_{\mathrm{sp}}\right)$, where: $\mathrm{pH}_{\text {prec. }}$ is the $\mathrm{pH}$ value above which hydroxides precipitate, $z$ is the cation valence, $c_{\mathrm{Me}}+z$ is the cation concentration in solution $\left[\mathrm{mol} / \mathrm{dm}^{3}\right], K_{\mathrm{sp}}$ is the solubility product constants $\left(\mathrm{p} K_{\mathrm{sp}}=-\log \left(K_{\mathrm{sp}}\right)\right.$, and hydroxides precipitate at $\mathrm{pH}=5.7$ from the copper salt solution with the concentration of $1 \mathrm{mmol} / \mathrm{dm}^{3}$.

Another approach in this area is the assessment of hydrogen cation participation in the process of ion-exchange. Our own studies reveal that depending on the biosorbent properties as well as the initial concentration of metal cations and $\mathrm{pH}$ of the solution, the hydrogen cations may be sorbed or desorbed in the solution. Figure 2 presents the changes 
of hydrogen cations, $c_{\mathrm{H}}$, in $\mathrm{CuSO}_{4}$ solutions of $200 \mathrm{~cm}^{3}$, the initial copper concentration of $\mathrm{mmol} / \mathrm{dm}^{3}$ and initial $\mathrm{pH}=4.6$, in which lichen Hypogymnia physodes, moss Pleurozium schreberi, and marine alga Palmaria palmate were immersed. For the purpose of this study, $1 \mathrm{~g}$ d.m. of each biosorbent was used.

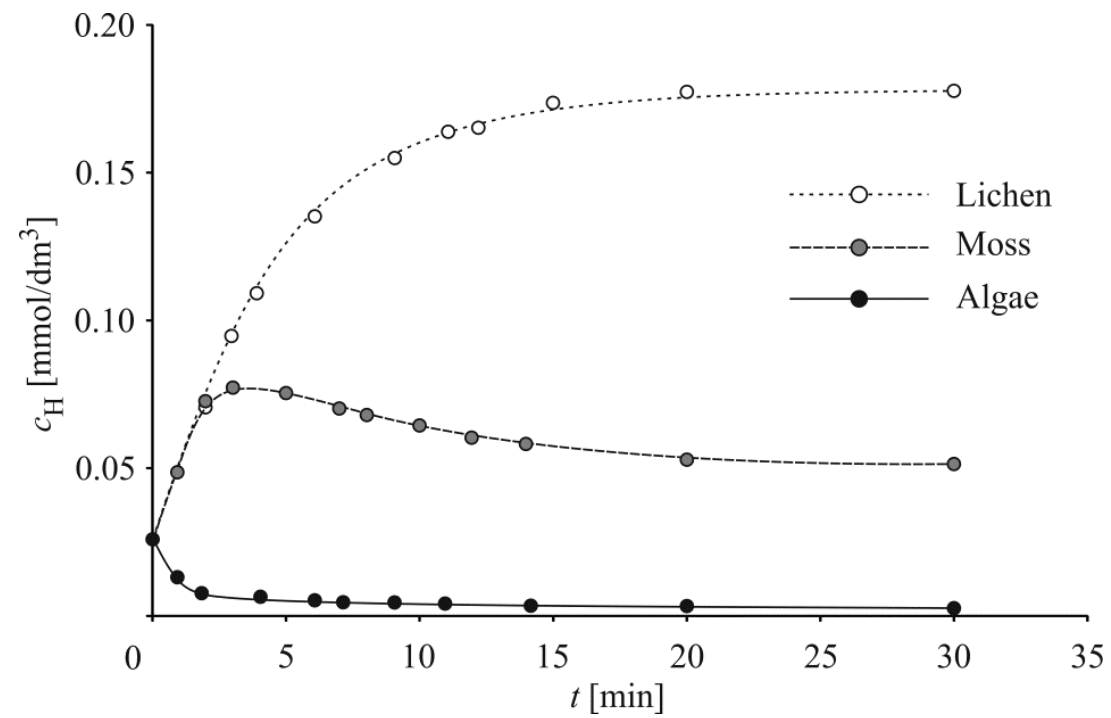

Fig. 2. Changes of hydrogen cations, $c_{\mathrm{H}}$, in $\mathrm{CuSO}_{4}$ solution during sorption by lichen Hypogymnia physodes, moss Pleurozium schreberi, and marine alga Palmaria palmate [31]

The results presented on the chart point to clear differences in changes of hydrogen cations concentrations in solutions in which the studied biosorbents were immersed. According to the chart, during the ion-exchange process lichens desorb the hydrogen cations, and moss initially desorbs and later sorbs, while in algae, there is a simultaneous sorption of copper cations and hydrogen cations. This is influenced by the cation-exchanging properties of biosorbents and the conditions of their vegetation. A characteristic feature of lichen is its ability to produce lichen acids [43]. Their amount, depending on the species, ranges from 0.5 to $10 \%$ of lichen dry mass. A natural lichen mechanism is acidification of its surroundings; therefore, in solutions, the sorption of heavy metals takes place with a simultaneous desorption of hydrogen cations [44]. The moss natural environment in terms of $\mathrm{pH}$ is similar to the conditions of the experiment. The registered non-monotonic changes of hydrogen cations concentration during the sorption process probably result from stabilisation of equilibrium between the $\mathrm{H}^{+}$and $\mathrm{Cu}^{2+}$ cations and the mobile cations desorbed from moss, e.g.: $\mathrm{Na}^{+}, \mathrm{K}^{+}, \mathrm{Ca}^{2+}$ and $\mathrm{Mg}^{2+}$. Also, other authors report the limited heavy metal sorption by cations which are naturally present in the environment $[15,27]$.

Algae behave in a dissimilar manner. Salt water, which is their natural environment, is slightly alkaline ( $\mathrm{pH}=7.5$ to 8.4 ); therefore, from the acid and slightly acid solutions (the initial $\mathrm{pH}$ of copper solution used in the experiment was 4.6), the sorption of hydrogen cations takes place simultaneously with the sorption of heavy metal cations. 
The examples presented substantiate the need to investigate the changes in $\mathrm{pH}$ of solutions during sorption. This enables the detection of possible changes of cation concentrations produced by the creation of insoluble chemical forms of metals during the experiment; also, it suggests a possible competitive sorption of hydrogen cations, especially at low metal concentrations in solution, which, as a consequence, has an effect on the measurement results.

\section{Effect of experiment conditions on the kinetics and sorption equilibrium parameters}

As mentioned in the introduction, to describe the kinetics of heavy metals sorption, the Lagergren model, pseudo-first order model (Eq. (1)) and pseudo-first order models (Eq. (2)) are frequently used. To describe parameters of the equilibrium state, the Langmuir isotherm model e.g. [45] is most frequently applied (Eq. (3)).

$$
\begin{gathered}
\ln \left(q_{M(1)}-q_{M(t)}\right)=\ln q_{M(1)}-k^{\prime} \cdot t \\
\frac{t}{q_{M(t)}}=\frac{1}{k^{\prime \prime} \cdot\left(q_{M(1)}\right)^{2}}+\frac{1}{q_{M(1)}} \cdot t \\
\frac{1}{q_{M(1)}}=\frac{1}{q_{M(\max )}}+\frac{1}{q_{M(\max )} \cdot K_{L}} \cdot \frac{1}{c_{M(1)}}
\end{gathered}
$$

where: $k^{\prime}$ and $k^{\prime}$ are constants of the pseudo-first and pseudo-second order reaction rates, respectively, $q_{M(t)}$ is the metal concentration in sorbent after time $t, q_{M(1)}$ is the metal concentration in the sorbent, which is in equilibrium with the concentration of this metal in solution: $c_{M(1)}, q_{M(\max )}$ is the sorbent sorption capacity, and $K_{L}$ is the Langmuir equilibrium constant.

The pseudo-second order reaction model used in this article was proposed and interpreted by Yuh-Shan Ho [46-48]. It should be noticed that this model can be used in determination of the analyte concentration in biosorbent in equilibrium state: $q_{M(1)}$.

\section{Sorption in the static system}

In the static system, the sorption kinetics parameters depend on the ratio of mass, volume and initial concentration of solution. It was found that the constant reaction rate is influenced by the initial solution concentration [30], but also, at the same initial concentrations, the ratio of sorbent mass to solution volume [49]. The reaction rate constant increases together with the increase of biosorbent mass [37]. Equilibrium parameters also undergo some changes. This was confirmed by the study of sorption processes of $\mathrm{Cu}^{2+}$ and $\mathrm{Ni}^{2+}$ cations depending on the mass of the applied alga Chlorella vulgaris [37], as well as the sorption of copper cations by the alga Spirogyra sp. [21].

Figure 3 presents temporal changes of copper concentration in Pleurozium schreberi during sorption. In the solution volume of $200 \mathrm{~cm}^{3}$ and at initial concentration of $0.08 \mathrm{mmol} / \mathrm{dm}^{3}$ the moss samples were immersed with their respective mass: $0.2,0.3,0.4$, $0.6,0.8$ and $1.0 \mathrm{~g} \mathrm{~d} . \mathrm{m}$. In the system of the static contact of biosorbent-solution, the kinetic and equilibrium parameters are most easily determined by the measurements of initial and final concentrations of solutions on which sorption was performed:

$$
q_{M(1)}=\frac{\left(c_{M(0)}-c_{M(1)}\right) \cdot V}{m}
$$


where: $V$ is the volume of solution on which sorption was performed, $m$ is the sorbent mass, and the indices (0) and (1) refer to the initial and final solution concentrations, respectively.

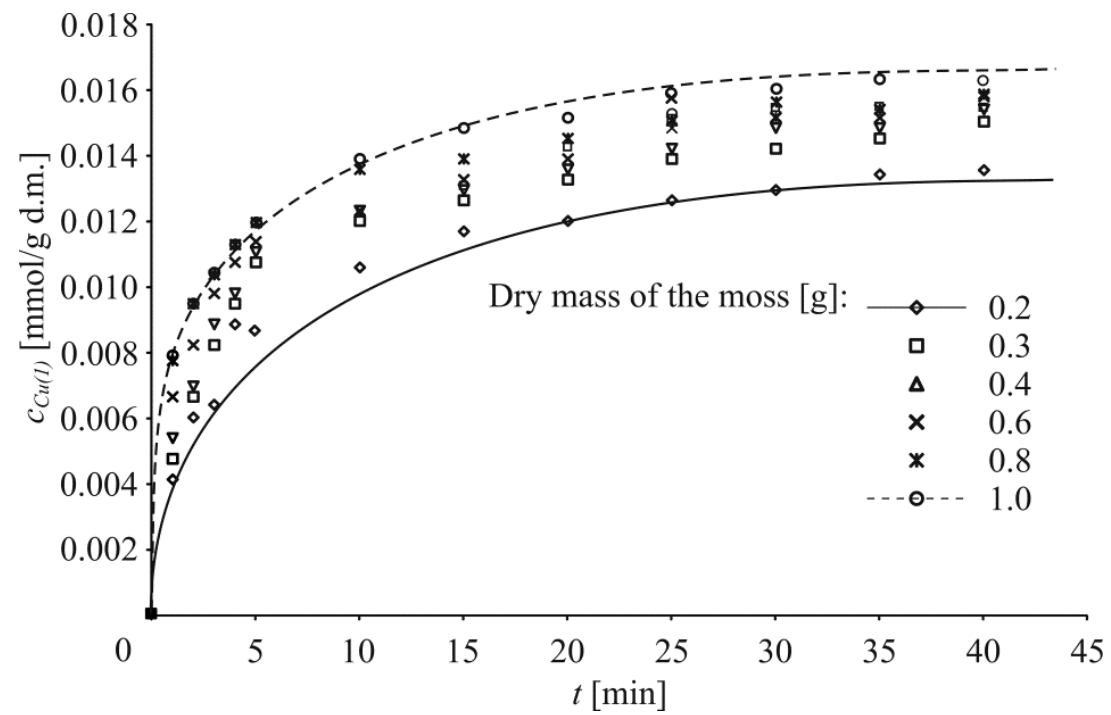

Fig. 3. Effect of the mass of moss Pleurozium schreberi on the changes of copper concentrations in solution during the sorption process

In Figure 4 lines with parameters calculated from pseudo-first and pseudo-second order (Eq. (1) and (2)) models are shown.

a)

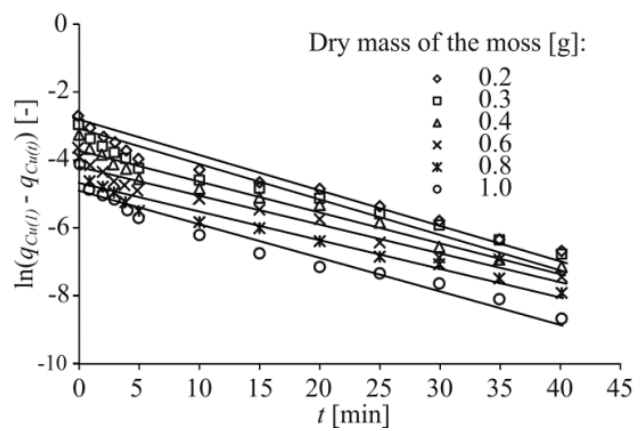

b)

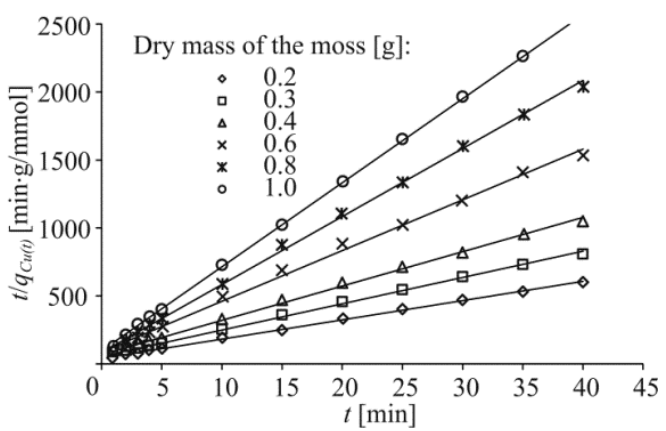

Fig. 4. Kinetics of copper sorption in moss Pleurozium schreberi described by: a) pseudo-first and b) pseudo-second order reaction model

Table 2 contains data collected regarding kinetic properties described by the reaction model of the pseudo-first and pseudo-second order, established on the basis of the results presented in Figure 4. The results, in compliance with dependence (4), were calculated at $1 \mathrm{~g} \mathrm{~d}$.m. of moss. 
Kinetic parameters of the process described by the reaction model of the pseudo-first (dependence (1)) and pseudo-second (dependence (2)) order

\begin{tabular}{|c|c|c|c|c|}
\hline \multirow{2}{*}{$\begin{array}{c}\text { Dry mass of } \\
\text { the moss }\end{array}$} & \multicolumn{2}{|c|}{ Pseudo-first order } & \multicolumn{2}{c|}{ Pseudo-second order } \\
\cline { 2 - 5 } & $\boldsymbol{q}_{\boldsymbol{C u}(\mathbf{1})}$ & $\boldsymbol{k}^{\prime}$ & $\boldsymbol{q}_{\boldsymbol{C u}(\mathbf{1})}$ & $\boldsymbol{k} \boldsymbol{~}$ \\
\hline$[\mathbf{g}]$ & {$[\mathbf{m m o l} / \mathbf{g}]$} & {$[\mathbf{1} / \mathbf{m i n}]$} & 0.0707 & 4.83 \\
\hline 0.2 & 0.0464 & 0.105 & 0.0517 & 6.73 \\
\hline 0.3 & 0.0309 & 0.084 & 0.0397 & 9.26 \\
\hline 0.4 & 0.0234 & 0.086 & 0.0268 & 15.9 \\
\hline 0.6 & 0.0148 & 0.082 & 0.0200 & 29.8 \\
\hline 0.8 & 0.0093 & 0.085 & 0.0162 & 39.9 \\
\hline 1.0 & 0.0074 & 0.099 & $\mathbf{m m o l})]$ \\
\hline
\end{tabular}

Data collected in Table 2 show that there are changes in sorption kinetics parameters depending on sorbent mass, which has been confirmed by other studies [30]. These data also point to a better adjustment of the pseudo-second order reaction model as well as to discrepancies in $c_{C u(m, 1)}$ values, i.e. different concentration values of copper accumulated in a mass unit of moss in equilibrium, determined on the basis of the applied models. It is interesting, however, that they are in a linear correlation: $q_{C u(1), k^{\prime \prime}}=1.4 \cdot q_{C u(1), k^{\prime}}$.

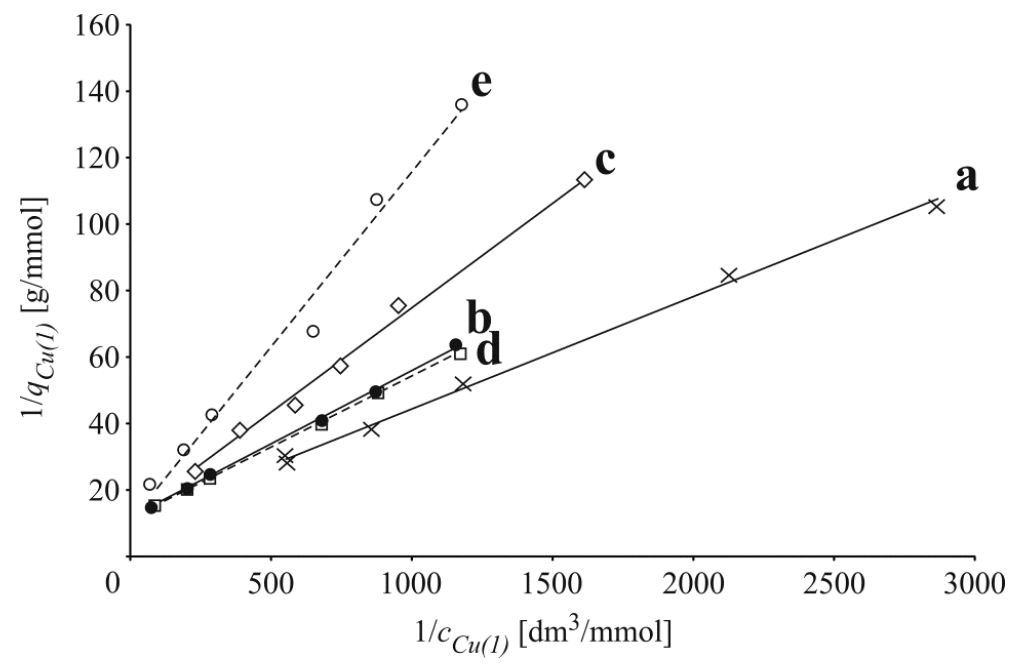

Fig. 5. Isotherms of copper sorption in moss Pleurozium schreberi: a $-m=$ const., $V=$ const., $\mathrm{b}-c_{C u(0)}=$ const., $V=$ const., $\mathrm{c}-c_{C u(0)}=$ const., $m=$ const., $\mathrm{d}-c_{C u(0)}=$ const., $V=$ const., $q_{C u(1), k \text {, }}$ $\mathrm{e}-c_{C u(0)}=$ const., $V=$ const., $q_{C u(1), k^{\prime}}[31]$

Langmuir isotherms (dependence (3)) are most frequently determined by measuring the equilibrium properties in the system of different initial concentrations of solution and constant volume of solution and sorbent mass, e.g. [50]. Their main aim is to assess the sorption capacity. However, it should be stressed that isotherms may also be determined in the system of different volumes of solution or different sorbent mass, at a constant initial concentration of solution. Figure 5 presents the isotherms localisation determined for copper in the following systems: a) different initial concentrations with a constant sorbent mass and solution volume, b) constant volume, constant initial concentration and different 
sorbent mass, c) constant sorbent mass, constant initial concentration and different solution volumes. Additionally, isotherms are presented, which are determined on the basis of $q_{C u(1)}$ concentration values determined from simple parameters describing the kinetics of reaction: d) the pseudo-second and e) the pseudo-first order (Table 2).

Determined sorption capacities are contained between $0.0841 \mathrm{mmol} / \mathrm{g}$ (isotherm $\mathrm{b}$ ) and $0.0920 \mathrm{mmol} / \mathrm{g}$ (isotherm a). A statistically significant assumption may be made that the isotherms (b) and (d) are the same. These isotherms were determined on the basis of data presented in Figure 3; however, as mentioned before, in order to draft isotherm (b), the values $q_{C u(1)}$ were used which were determined in accordance with dependence 4 , on the basis of measurements of copper concentration in the solution in the equilibrium state, while, in order to draft isotherm (d), the data from Table 2 were used, which were determined on the basis of directional coefficients of lines describing the reactions of pseudo-second order. This points to good correlations between the Langmuir model and the model describing the kinetics of the pseudo-second order reaction. It should be noted that the $q_{\mathrm{Cu}(1)}$ values determined from the pseudo-second order reaction model are usually larger than the values determined experimentally.

The issue to consider is the reason for changes in directional coefficients of lines described by the Langmiur model, which can be observed at the change of $\mathrm{V} / \mathrm{m}$ ratio, while maintaining the same initial concentrations of solutions on which sorption was performed. Many authors report this regularity, e.g. [37].

The Langmuir isotherm model, described by dependence (3), may be transformed into the following form:

$$
K_{L}=\frac{q_{M(1)}}{c_{M(1)}} \cdot \frac{1}{q_{M(\max )}-q_{M(1)}}
$$

and later, assuming that $q_{M(\max )}-q_{M(1)}=q_{R}{ }^{-}$, where $c_{R}{ }^{-}$is the concentration of the unfulfilled active spaces in the sorbent mass, $q_{M(1)}=q_{M R}$ is the concentration of metal bound in sorbent, and that $c_{M(1)}=c_{M}{ }^{+}$is the concentration of cations of the sorbed metal in solution, in equilibrium, it can be stated that:

$$
K_{L}=\frac{q_{M R}}{c_{M^{+}} \cdot q_{R}}
$$

i.e. that the Langmuir equilibrium constant describes the reaction equilibrium state:

$$
\mathrm{M}^{+}+\mathrm{R}^{-} \leftrightarrows \mathrm{MR}
$$

The kinetics of such a reaction is described by the pseudo-second order model, which, in turn, substantiates the fact that lines (b) and (d) overlap, which is presented in Figure 4.

It should be noted that the real process of ion-exchange of biosorbent-solution takes place until equilibrium is attained between the sorbed and desorbed cations in the biosorbent and in the solution. It is described by the equation of the heterophasic ion-exchange:

$$
\mathrm{M}^{+}+\mathrm{CtR} \leftrightarrows \mathrm{Ct}^{+}+\mathrm{MR}
$$

where $\mathrm{Ct}^{+}$is the cation desorbed due to ion-exchange.

As a consequence, while comparing equation (6) with the equilibrium constant of the heteropasic ion-exchange $K_{I E}$, which characterises the reaction described by equation (8) ( $\mathrm{R}^{-}$from equation (7) is equivalent with $\mathrm{CtR}$ from equation (8)), the following ratio can be determined: 


$$
K_{I E}=c_{C t^{+}} \cdot K_{L}
$$

Equilibrium of the ion-exchange suggests that, with the constant initial concentration of the sorbed metal in the solution $\left(c_{M(0)}=\right.$ const. $)$, the concentration of cations released into the solution due to ion-exchange increases with the increase of sorbent mass and decreases with the increase of solution volume. Therefore, in different conditions of the process, assuming that $K_{I E}=$ const., the value of $K_{L}$ changes, which influences the inclination of Langmuir isotherm: $\operatorname{tg} \alpha=1 / q_{M(\max )} \cdot K_{L}$, decreases together with the increase of $\mathrm{V} / \mathrm{m}$. Dependence (9) has a limited range since at $c_{C t}{ }^{+} \rightarrow 0$ the equilibrium is described by equation (7).

Regardless of the manner of sorption procedure, the kinetics and equilibrium state parameters are influenced by the temperature of the process $[15,26,30,50-52]$. The constant of reaction rate decreases together with the temperature increase.

To sum up, the number of active centres in a mass unit of sorbent should have a defined value which, in a constant temperature, remains unchanged in relation to a given cation. The chemical character of active centres may prefer the sorption of defined cations of heavy metals. Neither the Langmuir model nor the pseudo-second order reaction model provide for the interaction between the sorbed and desorbed cations, which, in turn, at the change of $V / m$ parameter, influences the value of directional coefficients of lines describing equilibria and kinetics of ion-exchange.

\section{Sorption in the dynamic system}

In the case of a dynamic flow of solution, it may be assumed that $c_{M(0)}=c_{M(1)}$ and that $c_{C t}^{+}=0$. In this case, the equilibrium is described by equation (7). This enables repeatable parameters required to determine the Langmiur isotherm to be obtained, which in a limited scope are independent from the mass of the applied sorbent. The disadvantages of this method are large volumes of solution used and a complicated measurement of kinetics parameters of the process. This method also requires determination of analytes in sorbent samples, as opposed to the static method, in which equation (4) may be applied.

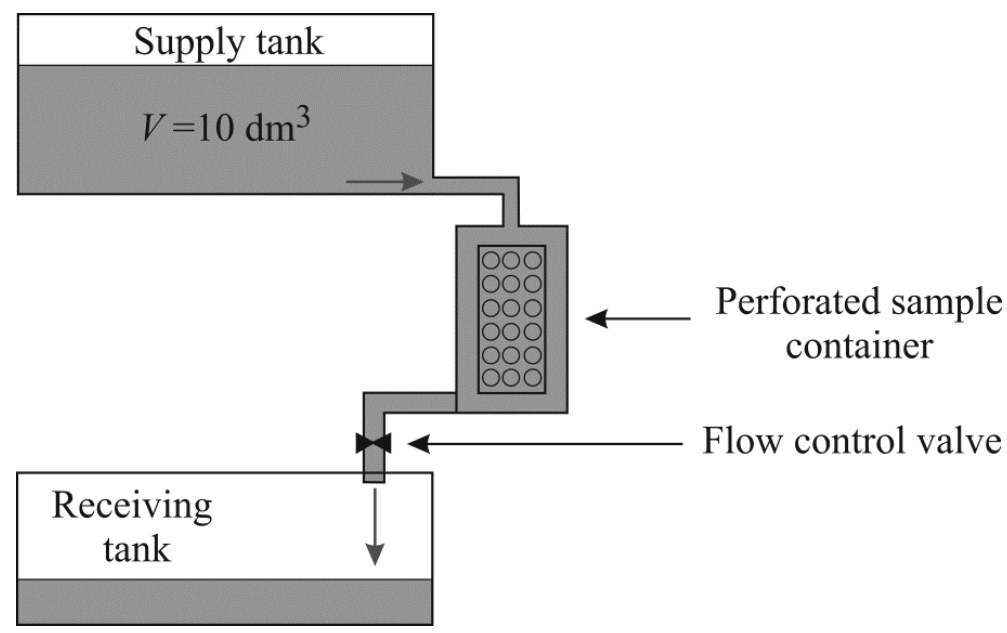

Fig. 6. Diagram of the set for determination of equilibrium parameters in the system of a dynamic solution flow 
Figure 6 presents the diagram of the set for determination of equilibrium parameters in the system of a dynamic solution flow.

Figure 7 presents Langmuir isotherms determined in the dynamic method for moss Pleurozium schreberi, lichen Hypogymnia physodes and alga Spirogyra sp. In order to determine the isotherm parameters, solutions of copper sulphate with the concentrations ranging from 0.015 to $0.080 \mathrm{mmol} / \mathrm{dm}^{3}$ were let through the samples of arbitrary mass ranging from $0.5-1.0 \mathrm{~g}$ d.m. Copper was determined in the solution and in biosorbent samples prior to and after sorption.

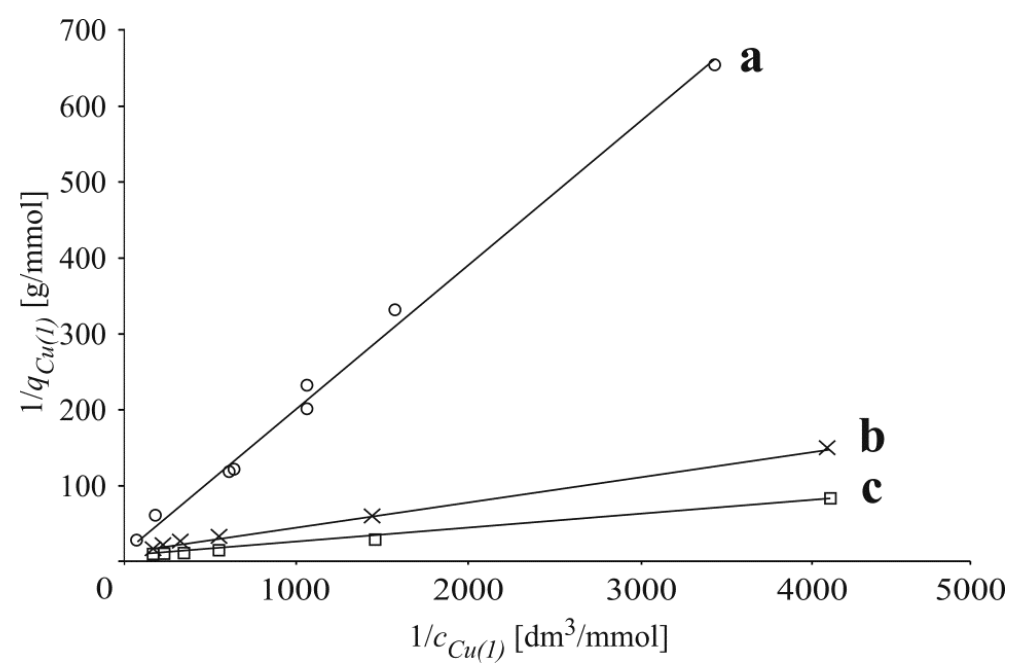

Fig. 7. Langmuir isotherms determined by the dynamic method for: a - Spirogyra sp., b - Hypogymnia physodes, c - Pleurozium schreberi

Detailed results together with the assessment of measurement uncertainty were presented in Table 4. It is important that, as opposed to the static method, this manner of conducting the study enables to compare equilibrium parameters regardless of the type of the studied biosorbents and applied proportions of biosorbent-solution, and, moreover, in relation to the processes of remediation or active biomonitoring of waters, it is comparable with real conditions. An advantage of this method is also the possibility of an arbitrary enrichment of solutions with chemical ingredients at their constant concentration during the experiment.

\section{Uncertainty of determination of parameters of equilibrium and kinetics of the ion-exchange processes}

As mentioned before, frequently the only given statistical parameter of lines determined from the dependences (1)-(3) is the determination coefficient $R^{2}$. Some authors additionally provide standard deviation determined from the series of experiment repetitions, e.g. $[7,15]$.

Our own studies reveal that significant statistical parameters are the standard error of the absolute term $a$ and the standard error of directional coefficient $b$ of the lines: $y=b \cdot x+a$, determined from the dependences (1)-(3). To determine standard errors of $a$ and 
$b$ coefficients, various statistical software packages and calculation sheets may be used, e.g. Excel or LibreOffice Calc. On the basis of these parameters, the uncertainty of determination of reactions rate constants as well as sorption capacities may be calculated. Tables 3 and 4 present collected statistical data regarding the $a$ and $b$ coefficients of lines describing kinetics of sorption process with the pseudo-first and pseudo-second order model (Fig. 4) and statistical data regarding the isotherms presented in Figures 5 and 7.

Table 3

Parameters of lines $y=b \cdot x+a$ describing the pseudo-first order reactions: $a=\ln q_{C u(1)}, b=-k$ ' and pseudo-second order: $a=\left(k " \cdot\left(q_{C u(1)}{ }^{2}\right)\right)^{-1}, b=\left(q_{C u(1)}\right)^{-1}$ with a given standard error $\pm S E$ of directional coefficients and absolute terms

\begin{tabular}{|c|c|c|c|c|c|c|c|c|c|c|}
\hline \multirow{2}{*}{$\begin{array}{c}\text { Dry mass of the } \\
\text { moss } \\
{[\mathrm{g}]}\end{array}$} & \multicolumn{5}{|c|}{ Pseudo-first order } & \multicolumn{5}{|c|}{ Pseudo-second order } \\
\hline & $a$ & $\pm S E_{a}$ & $b$ & $\pm S E_{b}$ & $R^{2}$ & $a$ & $\pm S E_{a}$ & $\boldsymbol{b}$ & $\pm S E_{b}$ & $R^{2}$ \\
\hline 0.2 & -3.07 & 0.14 & -0.1046 & 0.0081 & 0.943 & 41.4 & 3.5 & 14.14 & 0.17 & 0.999 \\
\hline 0.3 & -3.47 & 0.10 & -0.0844 & 0.0056 & 0.958 & 55.5 & 5.1 & 19.33 & 0.25 & 0.998 \\
\hline 0.4 & -3.75 & 0.10 & -0.0864 & 0.0060 & 0.954 & 68.6 & 7.2 & 25.20 & 0.35 & 0.998 \\
\hline 0.6 & -4.21 & 0.11 & -0.0829 & 0.0062 & 0.947 & 87 & 13 & 37.30 & 0.61 & 0.997 \\
\hline 0.8 & -4.67 & 0.13 & -0.0845 & 0.0078 & 0.922 & 94 & 11 & 50.04 & 0.54 & 0.999 \\
\hline 1.0 & -4.90 & 0.15 & -0.0991 & 0.0086 & 0.930 & 95.8 & 7.1 & 61.81 & 0.34 & 0.999 \\
\hline
\end{tabular}

Parameters of lines determined from the Langmuir isotherm model, presented in Figures 5 and 7: $a=\left(q_{C u(\max )}\right)^{-1}$, $b=\left(q_{C u(\max )} \cdot K_{L}\right)^{-1}, \pm S E$ - standard error, $R^{2}$ - determination coefficient, determined sorption capacity: $q_{C u(\max )}[\mathrm{mmol} / \mathrm{g}]$

\begin{tabular}{|c|c|c|c|c|c|c|c|}
\hline Isotherms & $a$ & $\pm S E_{a}$ & $b$ & $\pm S E_{b}$ & $R^{2}$ & $q_{C u(\max )}$ & $\pm S E_{q C u(\max )}[\%]$ \\
\hline Fig. 5, a & 10.9 & 2.3 & 0.0337 & 0.0011 & 0.996 & 0.092 & 16 \\
\hline Fig. 5, b & 11.9 & 1.1 & 0.0439 & 0.0016 & 0.995 & 0.084 & 9.2 \\
\hline Fig. 5, c & 11.8 & 2.3 & 0.0631 & 0.0026 & 0.993 & 0.085 & 20 \\
\hline Fig. 5, d & 11.2 & 1.1 & 0.0433 & 0.0016 & 0.995 & 0.090 & 9.8 \\
\hline Fig. 5, e & 11.3 & 4.9 & 0.1043 & 0.0073 & 0.981 & 0.087 & 43 \\
\hline Fig. 7, a & 15.1 & 9.8 & 0.1854 & 0.0066 & 0.992 & 0.066 & 65 \\
\hline Fig. 7, b & 12.9 & 1.5 & 0.0330 & 0.0084 & 0.997 & 0,077 & 12 \\
\hline Fig. 7, c & 8.53 & 0.92 & 0.0182 & 0.0005 & 0.997 & 0.117 & 11 \\
\hline
\end{tabular}

Statistical data presented in Table 3 show that the pseudo-second order model is better adjusted. On average, the standard error of $a$ and $b$ coefficients is approximately $1.5 \%$, while in the case of the pseudo-first order reaction model, this value is approximately $15 \%$. The determination coefficient also suggests a better adjustment.

The values of standard error determined for the biosorbent sorption capacities present themselves variously. Information in Table 4 suggests that the slightest error of sorption capacity determination in the static system is characteristic for the isotherm drafted in the conditions of $c_{C u(0)}=$ const., $V=$ const. (Fig. 5, b), determined from the lines describing kinetics of reaction of the pseudo-second order (Fig. 5, d), while in these two cases, the same conditions of process were maintained: different biosorbent mass, $c_{C u(0)}=$ const., $V=$ const. In the case of the alga Spirogyra spp., the uncertainty of determination of sorption capacity reaches $65 \%$. The studies revealed that depending on the experimental conditions, the uncertainty of determination of sorption capacity may exceed a determined value [34]. Data presented in Table 4 also suggest that the determination coefficient $R^{2}$ does not correlate with the values of standard errors; therefore, it should not be the only indicator of results reliability. 
Compared with the isotherms presented in Figure 5, the isotherm determined for moss Pleurozium schreberi in the dynamic system is characterised by the lowest value of the directional coefficient $\left(\left(q_{C u(\max )} \cdot K_{L}\right)^{-1}=0.0182\right)$ and the absolute term $\left(\left(q_{C u(\max )}\right)^{-1}=8.53\right.$, which, in accordance with the dependence (3), translates into the highest value of sorption capacity. As mentioned before, in the dynamic method, there are no interactions between the sorbed and desorbed cations. The results also suggest that sorption properties of the studied biosorbents, in relation to copper cations, change in the order: Pleurozium schreberi > Hypogymnia physodes > Spirogyra sp.

\section{Conclusions}

The presented study results suggest that various factors influence determination of sorption properties, mainly the manner of conducting the experiment, but also the manner of preparing and storing the samples, a competitive sorption, e.g. of hydrogen cations as well as interaction between cations of the sorbed heavy metals and the desorbed cations due to ion-exchange. An important element of the study is a statistical evaluation of the results showing the uncertainty of determined parameters, which, due to various factors, may reach significant values. It is possible that an optimal method which enables a comparison of equilibrium parameters of biosorbent-solution is the dynamic method, which in relation to the remediation processes or active biomonitoring of waters, is close to real conditions.

The conducted study shows that the assessment of sorption properties of various biosorbents requires the establishment of a joint concept for conducting studies and the interpretation of results.

\section{References}

[1] Bayramoglu G, Akbulut A, Acıkgoz-Erkaya I, Arica MY. J Appl Phycol. 2017;1-13. DOI: 10.1007/s10811-017-1238-8.

[2] Cheng J, Yin W, Chang Z, Lundholm N, Jiang Z. Biosorption capacity and kinetics of cadmium(II) on live and dead Chlorella vulgaris. J Appl Phycol. 2017;29:211-221. DOI: 10.1007/s10811-016-0916-2.

[3] Herrero R, Lodeiro P, Rey-Castro C, Vilariño T, Sastre de Vicente ME. Removal of inorganic mercury from aqueous solutions by biomass of the marine macroalga Cystoseira baccata. Water Res. 2005;39:3199-3210. DOI: 10.1016/j.watres.2005.05.041.

[4] Hauck M, Huneck S. Lichen substances affect metal adsorption in Hypogymnia physodes. J Chem Ecol. 2007;33:219-223. DOI: 10.1007/s10886-006-9225-6.

[5] Balarama Krishna MV, Chandrasekaran K, Rao SV, Karunasagar D, Arunachalam J. Speciation of Cr(III) and $\mathrm{Cr}(\mathrm{VI})$ in waters using immobilized moss and determination by ICP-MS and FAAS. Talanta. 2005;65:135-143. DOI: 10.1016/j.talanta.2004.05.051.

[6] Ferreira D, Ciffroy P, Tusseau-Vuillemin M-H, Garnier C, Garnier J-M. Modelling exchange kinetics of copper at the water-aquatic moss (Fontinalis antipyretica) interface: Influence of water cationic composition (Ca, Mg, Na and pH). Chemosphere. 2009;74:1117-1124. DOI: 10.1016/j.chemosphere.2008.10.031.

[7] Bhat SV, Melo JS, Chaugule BB, D'Souza SF. Biosorption characteristics of uranium(VI) from aqueous medium onto Catenella repens, a red alga. J Hazard Mater. 2008;158:628-635. DOI: 10.1016/j.jhazmat.2008.02.042.

[8] Srivastava S, Agrawal SB, Mondal MK. A review on progress of heavy metal removal using adsorbents of microbial and plant origin. Environ Sci Pollut Res. 2015;22:15386-15415. DOI: $10.1007 /$ s1 1356-015-5278-9.

[9] Ringqvist L, Holmgren A, Oborn I. Poorly humified peat as an adsorbent for metals in wastewater. Water Res. 2002;36:2394-2404. DOI: 10.1016/S0043-1354(01)00430-4.

[10] Jain CK, Malik DS, Yadav AK. Applicability of plant based biosorbents in the removal of heavy metals: a review. Environ Process. 2016;3:495-523. DOI: 10.1007/s40710-016-0143-5. 
[11] Ramrakhiani L, Ghosh S, Majumdar S. Surface modification of naturally available biomass for enhancement of heavy metal removal efficiency, upscaling prospects, and management aspects of spent biosorbents: A review. Appl Biochem Biotechnol. 2016;180:41-78. DOI: 10.1007/s12010-016-2083-y.

[12] Genc-Fuhrman H, Mikkelsen PS, Ledin A. Simultaneous removal of As, Cd, Cr, Cu, Ni and $\mathrm{Zn}$ from stormwater: Experimental comparison of 11 different sorbents. Water Res. 2007;41:591-602. DOI: 10.1016/j.watres.2006.10.024.

[13] Wu P, Zhou Y. Simultaneous removal of coexistent heavy metals from simulated urban stormwater using four sorbents: A porous iron sorbent and its mixtures with zeolite and crystal gravel. J Hazard Mater. 2009;168:674-680. DOI: 10.1016/j.jhazmat.2009.02.093.

[14] Kłos A, Rajfur M, Wacławek M, Wacławek W. Determination of the atmospheric precipitation pH value on the basis of the analysis of lichen cationactive layer constitution. Electrochim Acta. 2006;51:5053-5061. DOI: 10.1016/j.electacta.2006.03.039.

[15] Martins RJE, Pardo R, Boaventura RAR. Cadmium(II) and zinc(II) adsorption by the aquatic moss Fontinalis antipyretica: effect of temperature, $\mathrm{pH}$ and water hardness. Water Res. 2004;38:693-699. DOI: 10.1016/j.watres.2003.10.013.

[16] Sen Gupta B, Curran M, Shameem H, Ghosh TK. Adsorption characteristics of Cu and Ni on Irish peat moss. J Environ Manage. 2009;90:954-960. DOI: 10.1016/j.jenvman.2008.02.012.

[17] Ho YS, John Wase DA, Forster CF. Batch nickel removal from aqueous solution by sphagnum moss peat. Water Res. 1995;29:1327-1332. DOI: 10.1016/0043-1354(94)00236-Z.

[18] Li Z-Y, Guo S-Y, Li L. Study on the process, thermodynamical isotherm and mechanism of Cr(III) uptake by Spirulina platensis. J Food Eng. 2006;75:129-136. DOI: 10.1016/j.jfoodeng.2005.04.003.

[19] Saeed A, Iqbal M. Bioremoval of cadmium from aqueous solution by blackgram husk (Cicer arientinum). Water Res. 2003;37:3472-3480. DOI: 10.1016/S0043-1354(03)00175-1.

[20] Pipíška M, Horník M, Vortoch L, Augustín J, Lesný J. Biosorption of $\mathrm{Co}^{2+}$ ions by lichen Hypogymnia physodes from aqueous solutions. Biologia. 2007;62:276-282. DOI: 10.2478/s11756-007-0047-y.

[21] Uluozlu OD, Sari A, Tuzen M, Soylak M. Biosorption of $\mathrm{Pb}$ (II) and $\mathrm{Cr}$ (III) from aqueous solution by lichen (Parmelina tiliaceae) biomass. Bioresour Technol. 2008;99:2972-2980. DOI: 10.1016/j.biortech.2007.06.052.

[22] Chen Z, Ma W, Han M. Biosorption of nickel and copper onto treated alga (Undaria pinnatifida): Application of isotherm and kinetic models. J Hazard Mater. 2008;155:327-333. DOI: 10.1016/j.jhazmat.2007.11.064.

[23] Dhananjay Kumar, Pandey LK, Gaur JP. Evaluation of various isotherm models, and metal sorption potential of cyanobacterial mats in single and multi-metal systems. Colloids Surf B Biointer. 2010;81:476-485. DOI: 10.1016/j.colsurfb.2010.07.042.

[24] Gupta VK, Rastogi A, Saini VK, Jain N. Biosorption of copper(II) from aqueous solutions by Spirogyra species. J Colloid Interface Sci. 2006;296:59-63. DOI: 10.1016/j.jcis.2005.08.033.

[25] Romera E, Gonzàlez F, Ballester A, Blázquez ML, Muñoz JA. Comparative study of biosorption of heavy metals using different types of algae. Bioresour Technol. 2007;98:3344-3353. DOI: 10.1016/j.biortech.2006.09.026.

[26] Sari A, Tuzen M. Removal of mercury(II) from aqueous solution using moss (Drepanocladus revolvens) biomass: Equilibrium, thermodynamic and kinetic studies. J Hazard Mater. 2009;171:500-507. DOI: 10.1016/j.jhazmat.2009.06.023.

[27] Khan TA, Mukhlif AA, Khan EA, Sharma DK. Isotherm and kinetics modeling of $\mathrm{Pb}$ (II) and Cd(II) adsorptive uptake from aqueous solution by chemically modified green algal biomass. Model Earth Syst Environ. 2016;2:117. DOI: 10.1007/s40808-016-0157-z.

[28] Witek-Krowiak A, Mitek M, Pokomeda K, Szafran RG, Modelski S. Biosorption of cationic dyes by beech sawdust I. Kinetics and equilibrium modeling. Chem Process Eng. 2010;31:409-420. ISSN: 0208-6425.

[29] Aksu Z, İşoğlu İA. Removal of copper(II) ions from aqueous solution by biosorption onto agricultural waste sugar beet pulp. Process Biochem. 2005;40:3031-3044. DOI: 10.1016/j.procbio.2005.02.004.

[30] Sari A, Mendil D, Tuzen M, Soylak M. Biosorption of Cd(II) and Cr(III) from aqueous solution by moss (Hylocomium splendens) biomass: Equilibrium, kinetic and thermodynamic studies. Chem Eng J. 2008;144:1-9. DOI: 10.1016/j.cej.2007.12.020.

[31] Kłos A. Mchy w biomonitoringu środowiska (Mosses in Environmental Biomonitoring). Warszawa: WN PWN; 2017. ISBN: 9788301194345.

[32] Ribeiro RFL, Magalhães SMS, Barbosa FAR, Nascentes CC, Campos LC, Moraes DC. Evaluation of the potential of microalgae Microcystis novacekii in the removal of $\mathrm{Pb}^{2+}$ from an aqueous medium. $\mathrm{J}$ Hazard Mater. 2010;179:947-953. DOI: 10.1016/j.jhazmat.2010.03.097.

[33] Kłos A, Rajfur M, Wacławek M, Wacławek W. Heavy metal sorption in the lichen cationactive layer. Bioelectrochemistry. 2007;71:60-65. DOI: 10.1016/j.bioelechem.2006.12.005. 
[34] Rajfur M, Kłos A, Wacławek M. Sorption of copper(II) ions in the biomass of alga Spirogyra sp. Bioelectrochemistry. 2012;87:65-70. DOI: 10.1016/j.bioelechem.2011.12.007.

[35] Nuhoglu Y, Malkoc E, Gürses A, Canpolat N. The removal of Cu(II) from aqueous solutions by Ulothrix zonata. Bioresour Technol. 2002;85:331-333. DOI: 10.1016/S0960-8524(02)00098-6.

[36] Garty J, Weissman L, Cohen L, Karnieli A, Orlovsky L. Transplanted Lichens in and around the Mount Carmel National Park and the Haifa Bay Industrial Region in Israel: Physiological and Chemical Responses. Environ Res. 2001;85:159-176. DOI: 10.1006/enrs.2000.4222.

[37] Mehta SK, Gaur JP. Characterization and optimization of $\mathrm{Ni}$ and $\mathrm{Cu}$ sorption from aqueous solution by Chlorella vulgaris. Ecol Eng. 2001;18:1-13. DOI: 10.1016/S0925-8574(00)00174-9.

[38] Tuzen M, Sari A, Mendil D, Soylak M. Biosorptive removal of mercury(II) from aqueous solution using lichen (Xanthoparmelia conspersa) biomass: Kinetic and equilibrium studies. J Hazard Mater. 2009;169:263-270. DOI: 10.1016/j.jhazmat.2009.03.096

[39] Sari A, Mendil D, Tuzen M, Soylak M. Biosorption of palladium(II) from aqueous solution by moss (Racomitrium lanuginosum) biomass: Equilibrium, kinetic and thermodynamic studies. J Hazard Mater. 2009;162:874-879. DOI: 10.1016/j.jhazmat.2008.05.112.

[40] Ajjabi LCh, Chouba L. Biosorption of $\mathrm{Cu}^{2+}$ and $\mathrm{Zn}^{2+}$ from aqueous solutions by dried marine green macroalga Chaetomorpha linum. J Environ Manage. 2009;90:3485-3489. DOI: 10.1016/j.jenvman.2009.06.001.

[41] Singh A, Kumar D, Gaur JP. Removal of $\mathrm{Cu}(\mathrm{II})$ and $\mathrm{Pb}$ (II) by Pithophora oedogonia: Sorption, desorption and repeated use of the biomass. J Hazard Mater. 2008;152:1011-1019. DOI: 10.1016/j.jhazmat.2007.07.076.

[42] Kuśmierek K, Świątkowski A. Influence of $\mathrm{pH}$ on adsorption kinetics of monochlorophenols from aqueous solutions on granular activated carbon. Ecol Chem Eng. 2015;22:95-105. DOI: 10.1515/eces-2015-0006.

[43] Boustie J, Grube M. Lichens, a promising source of bioactive secondary metabolites. Plant Gen Res. 2005;3:273-287. DOI: 10.1079/PGR200572.

[44] Kłos A, Rajfur M, Wacławek M, Wacławek W. Ion equilibrium in lichen surrounding. Bioelectrochemistry. 2005;66:95-103. DOI: 10.1016/j.bioelechem.2004.04.006.

[45] Sharma SK, Mahiya S, Lofrano G. Removal of divalent nickel from aqueous solutions using Carissa carandas and Syzygium aromaticum: isothermal studies and kinetic modelling. Appl Water Sci. 2017;7:1855-1868. DOI: 10.1007/s13201-015-0359-y.

[46] Ho YS, McKay G. Sorption of dye from aqueous solution by peat. Chem Eng J. 1998;70:115-124. DOI: 10.1016/S0923-0467(98)00076-1.

[47] Ho YS. Citation review of Lagergren kinetic rate equation on adsorption reactions. Scientometrics. 2004;59:171-177. DOI: 10.1023/B:SCIE.0000013305.99473.

[48] Ho YS. Review of second-order models for adsorption systems. J Hazard Mater. 2006;136:681-689. DOI: 10.1016/j.jhazmat.2005.12.043.

[49] Grimm A, Zanzi R, Björnbom E, Cukierman AL. Comparison of different types of biomasses for copper biosorption. Bioresour Technol. 2008;99:2559-2565. DOI: 10.1016/j.biortech.2007.04.036.

[50] Rathinam A, Maharshi B, Janardhanan SK, Jonnalagadda RR, Nair BU. Biosorption of cadmium metal ion from simulated wastewaters using Hypnea valentiae biomass: A kinetic and thermodynamic study. Bioresour Technol. 2010;101:1466-1470. DOI: 10.1016/j.biortech.2009.08.008.

[51] Özer A, Özer D, Ekiz HI. The equilibrium and kinetic modeling of the biosorption of copper(II) ions on Cladophora crispate. Adsorption. 2004;10:317-326. DOI: 10.1007/s10450-005-4817-y.

[52] Yildiz S. Kinetic and isotherm analysis of $\mathrm{Cu}$ (II) adsorption onto almond shell (Prunus Dulcis). Ecol Chem Eng S. 2017;24(1):87-106. DOI: 10.1515/eces-2017-0007. 